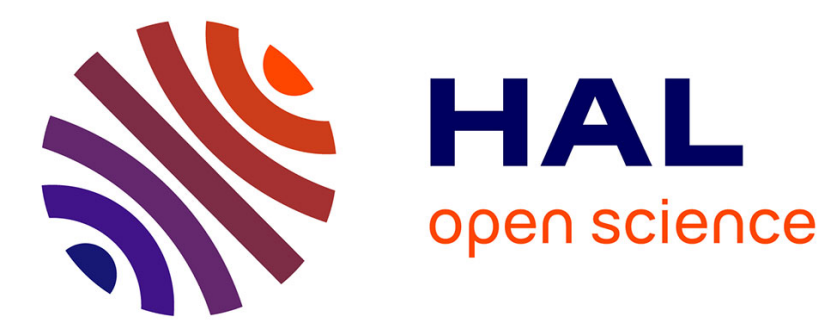

\title{
Low-Speed Longitudinal Controllers for Mass-Produced Cars: A Comparative Study
}

Vicente Milanés, Jorge Villagra, Joshué Pérez Rastelli, Carlos González

\section{To cite this version:}

Vicente Milanés, Jorge Villagra, Joshué Pérez Rastelli, Carlos González. Low-Speed Longitudinal Controllers for Mass-Produced Cars: A Comparative Study. IEEE Transactions on Industrial Electronics, 2012, 59 (1), pp.620-628. hal-00732892

\section{HAL Id: hal-00732892 \\ https://hal.inria.fr/hal-00732892}

Submitted on 1 Oct 2012

HAL is a multi-disciplinary open access archive for the deposit and dissemination of scientific research documents, whether they are published or not. The documents may come from teaching and research institutions in France or abroad, or from public or private research centers.
L'archive ouverte pluridisciplinaire HAL, est destinée au dépôt et à la diffusion de documents scientifiques de niveau recherche, publiés ou non, émanant des établissements d'enseignement et de recherche français ou étrangers, des laboratoires publics ou privés. 


\title{
Low-Speed Longitudinal Controllers for Mass-Produced Cars: A Comparative Study
}

\author{
Vicente Milanés, Jorge Villagrá, Joshué Pérez, and Carlos González, Member, IEEE
}

\begin{abstract}
Four longitudinal control techniques are compared: a classical Proportional-Integral (PI) control; an advanced technique-called the i-PI-that adds an intelligent component to the PI; a fuzzy controller based on human experience; and an adaptive-network-based fuzzy inference system. The controllers were designed to tackle one of the challenging topics as yet unsolved by the automotive sector: managing autonomously a gasoline-propelled vehicle at very low speeds. The dynamics involved are highly nonlinear and constitute an excellent test-bed for newly designed controllers. A Citroën C3 Pluriel car was modified to permit autonomous action on the accelerator and the brake pedals-i.e., longitudinal control. The controllers were tested in two stages. First, the vehicle was modeled to check the controllers' feasibility. Second, the controllers were then implemented in the Citroën, and their behavior under the same conditions on an identical real circuit was compared.
\end{abstract}

Index Terms-Autonomous vehicle, intelligent control, longitudinal control, nonlinear control.

\section{INTRODUCTION}

D RIVING in traffic jam conditions is one of the most challenging topics of large city traffic management. The data on Madrid (Spain) indicate that its almost one million workers every day waste more than 30 minutes at rush hours because of traffic jams. The estimated annual cost is more than 800 million euros [1]. This problem is being tackled by both the automotive industry and transport research groups with the goal of reducing these figures. With respect to the automotive sector, particular effort has been put into developing automatic vehicle speed control. The main aim of these controllers is to improve the safety of the car's occupants by relieving the human driver of tedious tasks so as to make driving easier, as well as making traffic flow more efficient. A first implementation was cruise control (CC) based on controlling the accelerator pedal [2]. This was then extended to adaptive CC (ACC) systems [3], developed to maintain a certain speed. A study of the impact of the widespread inclusion of CC systems can be found in [4], which finds, for instance, that there was a $50 \%$ reduction in

Manuscript received April 8, 2010; revised October 5, 2010 and March 9, 2011; accepted April 15, 2011. Date of publication May 2, 2011; date of current version October 4, 2011. This work was supported by the CYCIT (Spain) and Plan Nacional (Spain) from the GUIADE (P9/08) and TRANSITO (TRA200806602-C03-01) projects, respectively.

The authors are with the AUTOPIA Program of the Center for Automation and Robotics, Universidad Politécnica de Madrid-Consejo Superior de Investigaciones Científicas, 28500 Madrid, Spain (e-mail: vicente.milanes@csic.es; jorge.villagra@csic.es; joshue.perez@csic.es; carlos.gonzalez@csic.es).

Color versions of one or more of the figures in this paper are available online at http://ieeexplore.iee.org.

Digital Object Identifier 10.1109/TIE.2011.2148673 crashes with injuries to the vehicle's occupants. However, these commercial systems are as yet incapable of working at speeds below $15 \mathrm{~km} / \mathrm{h}$-obviously the case in traffic jams.

For urban environments, several advanced driver assistance systems (ADAS) [5] have been developed based on acoustics, haptics, or visual signals to warn the driver of potential collisions, but the trend for the future is for there to be a step taken from developing driving aids to developing automatic driving controls.

With these premises, research on autonomous systems capable of adapting a vehicle's speed in urban environments is one of the most important targets for the mid-term future of the market. Such systems, based on combined actions on the accelerator and brake pedals, are known as intelligent cruise control (ICC) [6]. Recent approaches to this problem have studied scaled vehicles [7], but gasoline-propelled vehicle dynamics at very low speeds are highly nonlinear and difficult to translate from a scaled vehicle to the real world.

Since the essential mechanism to generate friction or braking efforts is the tire-road interaction, which is a very complex phenomenon and depends on many poorly known factors, the control strategies chosen for this work have a common point: they are all based on model-free control approaches. As a result, the tracking results obtained here will a priori be valid for most of the vehicle at any stage of its lifetime cycle.

With these premises, the original contributions of this communication are twofold. On one hand, to tackle one of the challenging topics as yet unsolved by the automotive sector: managing autonomously a gasoline-propelled vehicle at very low speeds. On the other hand, to perform a comparative study of four longitudinal controllers: a classical ProportionalIntegral (PI) controller; an advanced technique-called the i-PI-that adds an intelligent component to the PI; a fuzzy controller based on human experience; and an adaptive-networkbased fuzzy inference system. These controllers were first tested in a simulation model. They were then translated to a mass-produced vehicle and tested on a real driving circuit, performing a comparative study of their behavior.

The rest of this paper organized as follows. Section II introduces the pre-requisites that have to be met by the controllers based on the comfort of the car's occupants. Section III presents the model of the vehicle, and the controllers that were designed are described in Section IV. The simulation results of the four controllers are compared in Section V. Section VI describes the mass-produced vehicle capable of managing accelerator and brake pedals, and Section VII presents the results using the real car. Finally, some concluding remarks are given in Section VIII. 

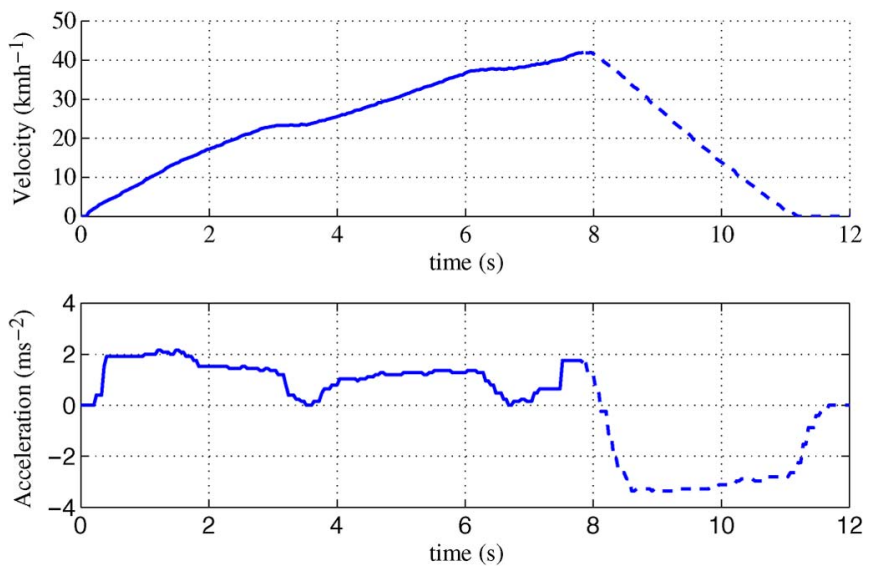

Fig. 1. Experimental results of the vehicle's behavior with a human driver.

\section{Prerequisites}

Various prerequisites were set to ensure an objective comparison of the four proposed autonomous longitudinal control techniques.

For the vehicle's speed control, priority was assigned to the occupants' comfort. The so-called Comfort Driving is an imprecise term whose limits may be taken at different values. A consensus widely accepted in the automotive sector is that given in [8], in which the maximum comfort acceleration is fixed at $2 \mathrm{~m} / \mathrm{s}^{2}$.

Given this basic target for comfort, we performed various tests to determine the maximum acceleration and the decelerations that might be experienced in the mass-produced car. For the acceleration, a human driver drove the vehicle from motionless with the accelerator (throttle) pedal pressed completely down. The car's behavior is shown in Fig. 1 (solid line). The upper plot is the vehicle's speed during the test, and the lower plot is its acceleration. The sampling interval was fixed by the parameters of the Controller Area Network (CAN) bus at $40 \mathrm{~ms}$ ( $25 \mathrm{~Hz}$ sampling rate). One observes that the acceleration exceeds the comfort value only slightly in the first instants-while the automatic gearbox is in first gear. Once the speed surpasses $15 \mathrm{~km} / \mathrm{h}$, the acceleration decreases to around $1.5 \mathrm{~m} / \mathrm{s}^{2}$. The values where the acceleration is null correspond to automatic gear changes, which are also reflected in small variations from smoothness in the speed curve.

In sum, therefore, the vehicle's maximum acceleration is in line with the comfort acceleration of $2 \mathrm{~m} / \mathrm{s}^{2}$, so that the entire accelerator pedal range is allowed.

The electro-hydraulic braking system installed in the vehicle was designed to allow emergency braking and sharp deceleration [9]. Given one of the purposes of the work (avoiding collisions in automatic driving), the allowed braking force engineered into the system was oversized relative to what would be required for comfortable driving. We therefore measured experimentally the deceleration generated for several constant pressure input values in order to determine the comfort values. To this end, automatic braking was activated via software at a constant pressure. The dashed line in Fig. 1 shows the speed and deceleration in one of these trials with $20 \%$ opening of the electro-proportional pilot. In the lower part of the figure, one observes that the deceleration values reached around $-3 \mathrm{~m} / \mathrm{s}^{2}$. This suggests that values higher than a $20 \%$ opening are not to be considered for comfortable control.

Once the maximum action allowable on the accelerator and brake pedals had been determined, the variables used to perform the control were defined. To this end, only values provided by the on-board sensors in the mass-produced vehicle were permitted, i.e., those provided via the CAN bus. In particular, the vehicle's actual speed and acceleration-obtained from a differential Hall Effect sensor and a piezoelectric sensor, respectively-were used as input variables. The reference (target) speed was generated via software. The frequency of actions on the pedals was set by the vehicle's CAN bus $-25 \mathrm{~Hz}$.

\section{Mathematical Model of the CAR}

The balance of forces along the vehicle's longitudinal axis (cf. [10]) gives

$$
M \dot{V}_{x}=F_{x}-F_{a}-R_{x}-M g \sin \theta
$$

where $M$ is the mass of the vehicle, $V_{x}$ the longitudinal velocity, $F_{x}$ the sum of all four longitudinal tire forces, $R_{x}$ the sum of all four tire forces due to rolling resistance, $\theta$ the angle of inclination of the road, and $F_{a}$ the longitudinal aerodynamic drag force.

The rolling resistance forces are often modeled as a linear function of normal forces on each tire, i.e., $R_{x}=k_{r} F_{z}$, with $k_{r}$ the rolling resistance coefficient and $F_{z}$ the vertical load of the vehicle.

The aerodynamic forces can be expressed as

$$
F_{a}=\frac{1}{2} \rho C_{d} A_{F}\left(V_{x}+V_{w i n d}\right)^{2}
$$

with $\rho$ being the mass density of air, $C_{d}$ the aerodynamic drag coefficient, $A_{F}$ the frontal area of the vehicle (the projected area of the vehicle in the direction of travel), and $V_{\text {wind }}$ the wind speed.

Finally, the Pacejka model [11] is used for each longitudinal tire/road interaction force, $F_{x_{i}}$. They depend on many factors, but essentially on longitudinal slip $\tau_{i}$, normal forces $F_{z_{i}}$, and the coefficient of friction $\mu_{i}$

$$
F_{x_{i}}=f\left(\tau_{i}, F_{z_{i}}, \mu_{i}\right), \quad i=1 \ldots 4
$$

where the slip ratio of each wheel is defined as

$$
\begin{cases}\tau=\frac{\omega_{i} r-V_{x}}{V_{x}} & \text { if } V_{x}>\omega_{i} r, V_{x}>0 \\ \tau=\frac{\omega_{i} r-V_{x}}{\omega_{i} r} & \text { if } V_{x}<\omega_{i} r, \omega_{i} r>0\end{cases}
$$

with $r$ being the wheel radius and $\omega_{i}$ the wheel angular velocity. Since longitudinal slip is usually small $(\tau \leqslant 0.05)$, the tractive and braking forces can be simplified [10] as

$$
F_{x_{i}}=C_{x_{i}} \tau_{i}
$$

being $C_{x_{i}}$ a fundamental parameter intrinsic to the tire/road interaction, called longitudinal stiffness coefficient. The rotation 
TABLE I

MOdel PARAMEters

\begin{tabular}{|c|c|}
\hline Parameter & Nominal Value \\
\hline$M$ & 1418 \\
$C_{d}$ & 0.32 \\
$A_{F}$ & 2.4 \\
$C_{x_{i}}$ & 40000 \\
$r$ & 0.21 \\
$I_{i}$ & 2 \\
$n$ & 25 \\
$\tau_{m}$ & 190 \\
$\beta_{m}$ & 0.4 \\
$\omega_{m}$ & 420 \\
$K_{b}$ & 220 \\
$\eta_{b}$ & 0.45 \\
$\omega_{b}$ & 1023 \\
\hline
\end{tabular}

dynamics of each wheel can be expressed as

$$
I_{i} \dot{\omega}_{i}=-r F_{x_{i}}+\tau_{e_{i}}-\tau_{b_{i}}
$$

where $I_{i}$ is the wheel's moment of inertia, $r$ the tire radius, $\tau_{e_{i}}$ the applied engine torque and $\tau_{b_{i}}$ the brake torque, both applied to each wheel's center.

The total engine torque $\tau_{e}$ can be expressed in terms of the throttle opening $u_{e}$ by the expression [12]

$$
\tau_{e}=n u_{e} \tau_{m}\left(1-\beta_{m}\left(\frac{\omega}{\omega_{m}}-1\right)^{2}\right)
$$

where $n$ is the gear ratio, $\omega$ is the average wheel speed, $\beta_{m}$ is an engine torque parameter, and the maximum torque $\tau_{m}$ is obtained at engine speed $\omega_{m}$.

Finally, the dynamics between the braking control variable $u_{b}$ and braking torque $\tau_{b}$ can be modeled as a second-order linear system [13]

$$
\tau_{b}(s)=\frac{K_{b}}{s^{2}+2 \eta_{b} \omega_{b} s+\omega_{b}^{2}} u_{b}(s)
$$

with $K_{b}, \eta_{b}$, and $\omega_{b}$ the static gain, damping factor, and natural frequency, ${ }^{1}$, respectively. All the numerical values of the model parameters are given in Table I.

\section{Design of the Controllers}

This section will describe the four control techniques used for the mass-produced car's speed control.

\section{A. PI Controller}

A PID controller is very useful for resolving a wide range of control problems. Indeed, more than $95 \%$ of all industrial control problems are resolved with PID control [12].

The control action is a sum of three terms: the past as represented by the integral of the error, the present as represented by the proportional term, and the future as represented by a linear extrapolation of the error (the derivative term).

\footnotetext{
${ }^{1}$ Since the braking dynamics is much faster than that of the vehicle, it can be replaced in the vehicle model by an algebraic expression, without loss of realism [14].
}

TABLE II

PI AND i-PI CONTROL PARAMETERS

\begin{tabular}{|l|l|l|l|l|l|l|}
\hline Controller & $\mathbf{K}_{\mathbf{p}_{\mathbf{e}}}$ & $\mathbf{K}_{\mathbf{i}_{\mathbf{e}}}$ & $\alpha_{\mathbf{e}}$ & $\mathbf{K}_{\mathbf{p}_{\mathbf{b}}}$ & $\mathbf{K}_{\mathbf{i}_{\mathbf{b}}}$ & $\alpha_{\mathbf{b}}$ \\
\hline $\mathbf{P I}$ & 0.1 & 1 & - & 0.05 & 0.005 & - \\
$\mathbf{i}-\mathbf{P I}$ & 0.1 & 1 & 80 & 0.05 & 0.005 & 100 \\
\hline
\end{tabular}

Many of these controllers are actually PI because derivative action is either unnecessary or difficult to tune. Thus, a PI controller $u$ will be classically tuned (cf. e.g., [12]) to reduce the velocity error

$$
u(t)=K_{P} e(t)+K_{I} \int e(t) d t, \quad e=V_{r}-V_{x}
$$

with proportional $K_{P}$ and integral $K_{I}$ gains.

More specifically, parameters $K_{P}$ and $K_{I}$ will be optimized to minimize the velocity Integral Absolute Error (IAE)

$$
I A E=\int_{0}^{T}\left(V_{x}-\dot{V}_{s}\right) d t
$$

where $\dot{V}_{s}$ is the first derivative of a smoothed reference speed, while respecting the maximum confort longitudinal acceleration. The results of this optimization process is shown in Table II.

\section{B. $i$-PI Controller ${ }^{2}$}

As given in [18], a finite-dimensional nonlinear system can be written locally as

$$
y^{(\mu)}=F+\alpha u
$$

where $\alpha \in \mathbb{R}$ and $\mu \in \mathbb{N}$ are two constant parameters, which do not necessarily represent physical magnitudes and whose choice is based on the following guidelines:

- $\mu$ is usually 1 or 2 , and may represent the system order, but not necessarily.

- $\alpha$ should allow $F$ and $\alpha u$ to be of the same order of magnitude.

The term $F$, which is a sort of nonlinear black-box identifier ${ }^{3}$ [18], [20], is computed with the input value at the preceding sample time $u\left(t_{k-1}\right)$ and with the $\mu$ th derivative estimate of the output $\left[y^{(\mu)}\left(t_{k}\right)\right]_{e}$ at the current sample time

$$
F\left(t_{k}\right)=\left[y^{(\mu)}\left(t_{k}\right)\right]_{e}-\alpha u\left(t_{k-1}\right)
$$

Combining the sum of the four wheel dynamics (2) and (1), one obtains a differential relationship between vehicle speed

\footnotetext{
${ }^{2}$ Note that this notation is not related to artificial intelligence techniques (cf. e.g., [15]-[17]), but rather to the capacity to complete automatically what a standard linear controller is unable to do.

${ }^{3}$ It is worth mentioning that Time Delay Controllers, presented in [19] uses similar techniques to identify and compensate unknown dynamics and disturbances.
} 
and brake/engine torques

$$
\begin{aligned}
\dot{V}_{x} & =\frac{1}{M r}\left(\tau_{g}-\sum_{i=1}^{4} I_{i} \dot{\omega}_{i}+G(t)\right) \\
G(t) & =r\left(F_{a}-R_{x}-M g \sin \theta\right)
\end{aligned}
$$

where $\tau_{g}=\sum_{i=1}^{4} \tau_{e_{i}}-\tau_{b_{i}}$ is a generalized torque applied to the vehicle-which will be positive or negative according to whether the throttle or brake are active.

The acceleration and braking dynamics will be neglected locally with respect to the vehicle dynamics. Consequently, an algebraic expression will be considered to approximate the relationships between engine torque $\tau_{e}=\sum_{i=1}^{4} \tau_{e_{i}}$ and a normalized voltage $\left(u_{e}=K_{e} \tau_{e}, u_{e} \in[0-1]\right)$, and between braking torque $\tau_{b}$ and a normalized voltage equivalent to the braking pressure $P_{f}\left(u_{b}=K_{b}^{\prime} P_{f}=K_{b} \tau_{b}=K_{b} \sum_{i=1}^{4} \tau_{b_{i}}\right)$.

Using the formalism introduced in (4), (6) can be expressed as

$$
\dot{V}_{x}(t)=F(t)+\alpha u(t), \quad \alpha=\left\{\alpha_{e}, \alpha_{b}\right\}, \quad u=\left\{u_{e}, u_{b}\right\}
$$

where $F=\left(G-\sum_{i=1}^{4} \dot{I}_{i} \omega_{i}\right) / M r, \quad \alpha_{e}=1 / M r K_{b}, \quad \alpha_{b}=$ $1 / M r K_{b}$ and $u=\tau_{g}$ is the control variable.

If (7) is inverted and merged with a PI controller [12], the resulting i-PI control law yields

$$
u=\frac{1}{\alpha}\left(\dot{V}_{s}-F\right)+K_{P} e+K_{I} \int e d t, \quad e=V_{x}-\dot{V}_{s}
$$

where $K_{P}, K_{I} \in \mathbb{R}^{+}$are PI-tuned gains (see Table II).

Remark 1: In adaptive or predictive control, a precise model of the overall system is commonly sought to properly optimize or adapt the control action to any situation. The control paradigm presented here aims to define a reference trajectory in accordance with system dynamics, so that controller actions are as smooth as possible and do not exceed saturation limits. The algorithm presented in [21] will be used to transform in realtime any step into a smooth reference that guarantees maximum acceleration and jerk compatible with the brake and motor systems.

Equation (8) can be particularized in the present case to control the throttle

$$
\begin{aligned}
u_{e}\left(t_{k}\right)= & \frac{1}{\alpha_{e}}\left(\dot{V}_{s}\left(t_{k}\right)-F_{e}\left(t_{k}\right)\right)+K_{p_{e}} e\left(t_{k}\right) \\
& +K_{i_{e}} \int\left(e\left(t_{k}\right)\right) d t \\
F_{e}\left(t_{k}\right)= & \gamma_{x}\left(t_{k}\right)-\alpha_{e} u_{e}\left(t_{k-1}\right), \quad \alpha_{e}=\frac{1}{M r K_{e}}
\end{aligned}
$$

and likewise with the brake

$$
\begin{aligned}
u_{b}\left(t_{k}\right)= & \frac{1}{\alpha_{b}}\left(\dot{V}_{s}\left(t_{k}\right)-F_{b}\left(t_{k}\right)\right)+K_{p_{b}} e\left(t_{k}\right) \\
& +K_{i_{b}} \int\left(e\left(t_{k}\right)\right) d t \\
F_{b}\left(t_{k}\right)= & \gamma_{x}\left(t_{k}\right)-\alpha_{b} u_{b}\left(t_{k-1}\right), \quad \alpha_{b}=\frac{1}{M r K_{b}}
\end{aligned}
$$
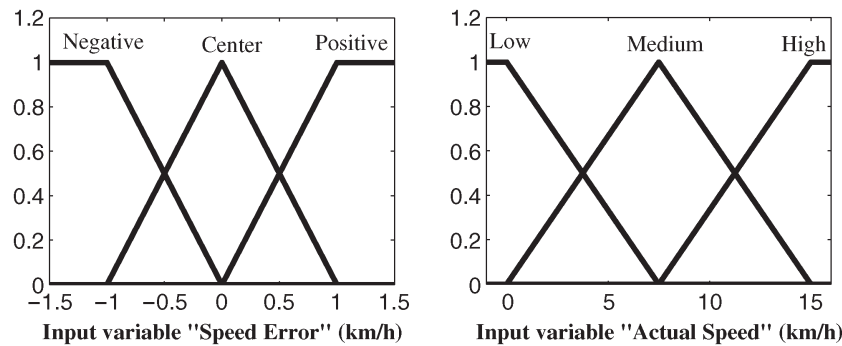

Fig. 2. Membership function definitions for the input variables (fuzzy controller).

where $\gamma_{x}\left(t_{k}\right) \approx \dot{V}_{x}\left(t_{k}\right)$ is the longitudinal acceleration provided by the CAN bus.

Finally, a decision rule will be established to determine whether braking or accelerator actions are needed. The control law of (10) will be applied if the speed setpoint is decreased. Since the motor exhibits much slower dynamics than the brake, when the smooth reference value is too close to its desired final target in this braking manuever, a possible accelerator action-(9) - will be allowed. In any other case, the accelerator control law (9) will be used. Even though this decision rule might seem too simple, it will be shown that it works properly and avoids the undesired effects of chattering between braking and accelerating actions [22].

Finally, note that PI and i-PI optimal gains for the proportional and integral actions are identical. The $\alpha$ parameter of i-PI, both for brake and throttle, has been manually obtained once the pure PI parameters were optimized.

\section{Fuzzy Controller}

The fuzzy controller developed consists of a rule base containing expert knowledge and a set of variables representing linguistic values. Although a vehicle presents highly nonlinear behavior, a human driver is capable of driving based on experience. We use this human experience as expert knowledge in order to design a controller capable of controlling the vehicle's speed at very low speeds. The tuning process was experimentally carried out with the idea of mimicking human driver behavior. In this connection, the fuzzy input variables were chosen as intuitive as possible. Final readjustments were carried out by trial and error procedure - as human drivers do to adapt the speed. As starting point, the pre-requisites presented in Section II have to be taken into consideration. Two variables are used as inputs:

Speed error is defined as the difference between the target speed and the actual speed, in $\mathrm{km} / \mathrm{h}$. It contains three membership functions - one for each of its three associated linguistic labels (see left side of Fig. 2). The Negative linguistic label represents the cases where the actual speed is significantly greater than the target speed, and the brake pedal has to be pressed. The Positive linguistic label indicates that the actual speed is lower than the target so that the accelerator pedal has to be pressed. Finally, the Center linguistic label includes the values where the speed error is close to zero.

Actual speed, in $\mathrm{km} / \mathrm{h}$. This variable is introduced to make smoother target speed changes. Given that the maximum 
TABLE III

FuzZy CONTROLler Rule BASE

\begin{tabular}{|c|c|c|c|}
\cline { 2 - 4 } \multicolumn{1}{c|}{} & \multicolumn{3}{c|}{ Speed Error } \\
\hline Actual Speed & Negative & Centre & Positive \\
\hline Low & -0.08 & 0.15 & 0.3 \\
\hline Medium & -0.1 & 0.2 & 0.35 \\
\hline High & -0.15 & 0.25 & 0.4 \\
\hline
\end{tabular}

acceleration allowed is $2 \mathrm{~m} / \mathrm{s}^{2}$, its behavior differs according to the initial speed when a target speed change occurs (see Fig. 1). This fuzzy input also has three membership functions defined one for each one of its three associated linguistic labels (see right side of Fig. 2). Given that the controller is designed for very low speeds, the Low linguistic label represents cases when the vehicle's speed is close to the moment when the vehicle is started. The High linguistic label detects when the vehicle's speed is close to the maximum speed allowed$15 \mathrm{~km} / \mathrm{h}$. A central membership function is included with the Medium linguistic label.

The output variable is Pedal. This determines which actuator has to be pressed, and the magnitude of the action. The fuzzy output variable's membership function shape is defined using Sugeno singletons which are based on monotonic functions. The possible output values are within the range $[-1,1]$, where -1 indicates the brake pedal is completely depressed and 1 indicates the maximum action is applied to the accelerator pedal. The output values assigned for each rule were determined experimentally, and are listed in Table III.

The main advantage of this controller is that it is easily readjusted since it consists of intuitive rules aimed at imitating human drivers.

\section{Neuro-Fuzzy Controller}

Following the development by Tagaki and Sugeno of a fuzzylogic-based controller [23], many industrial processes are now controlled using the knowledge of expert operators. The main advantage of a fuzzy controller is that an exact mathematical model of the system is unnecessary. The control problem is reduced to estimating the input, establishing a rule base, and assigning the output values.

Nevertheless, for a large class of fuzzy applications, there are no standard methods for transforming human experience into the fuzzy system's rule base and database, and the problem is compounded as more variables are added into the control loop.

Neuro-fuzzy systems combine the easy handling of if-then rules with the learning capacity of neural networks [24]. One of the most extensively used and successful in terms of the quality of its results is the adaptive-neuro-fuzzy inference system (ANFIS) [24], which combines a back propagation algorithm with a least squares method. There has been a recent application to improve speed tracking and the comfort of the vehicle in a simulation [25]. Also, some of the latest work of our group [26] has shown that previous fuzzy controllers can be improved by incorporating the experience of expert drivers via a neuro-fuzzy system, but, although the driving achieved was more comfortable, there was still a large speed reference error (around $1.59 \mathrm{~km} / \mathrm{h}$ ) [26].
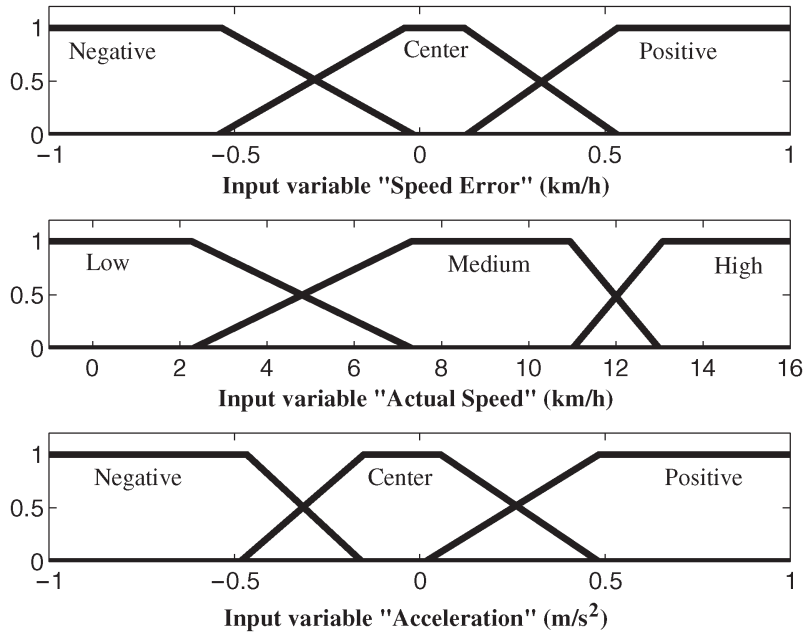

Fig. 3. Membership function definitions for the input variables (neuro-fuzzy controller)

TABLE IV

RULE BASE FOR SPEED ERROR = NEGATIVE

\begin{tabular}{|c|c|c|c|}
\cline { 2 - 4 } \multicolumn{1}{c|}{} & \multicolumn{3}{c|}{ Acceleration } \\
\hline Actual Speed & Negative & Centre & Positive \\
\hline Low & -0.083 & -0.072 & -0.91 \\
\hline Medium & -0.121 & -0.062 & -0.117 \\
\hline High & -0.16 & -0.127 & -0.13 \\
\hline
\end{tabular}

The controllers described above in the present work- the i-PI and fuzzy controllers-provide the basis on which to generate a new controller using neuro-fuzzy techniques. It is essential to begin with a good database on which to train the neural network and to generate the membership functions, the rules, and the output using Sugeno singletons for the neuro-fuzzy controller. This database will contain the measured input and the desired output. Given the difficulty in measuring the pressure of both pedals in real time while following a reference speed, in the present work we selected the best trials with the other controllers to train the neuro-fuzzy controller. In particular, we considered the steady state behavior of the i-PI and the transient state behavior of the fuzzy controller with which to apply the ANFIS learning strategies. An extensive experimental validation was carried out to check the system stability in urban environment situations at low speeds.

A new controller has been estimated using adaptive neuronalnetwork (ANFIS). The proposed neuro-fuzzy controller has three input variables (actual speed, acceleration, and speed error) and one output variable (pedal). The actual speed and the speed error have the same meaning as in the previous fuzzy controller section. The acceleration is measured in meters per second squared $\left(\mathrm{m} / \mathrm{s}^{2}\right)$, and is defined as the derivative of the actual speed at a given instant of time. Its linguistic representation is divided into three values: negative, center, and positive. Fig. 3 shows the shapes of the input membership functions. The output range is $[-1,1]$ as in the fuzzy controller. These possible values are proportional to the number of rules generated by ANFIS. Because there are three input variables with three linguistic values, 27 rules are generated. Tables IV-VI present the rule bases generated. 
TABLE V

RULE BASE FOR SPEED ERROR $=$ CENTER

\begin{tabular}{|c|c|c|c|}
\cline { 2 - 4 } \multicolumn{1}{c|}{} & \multicolumn{3}{c|}{ Acceleration } \\
\hline Actual Speed & Negative & Centre & Positive \\
\hline Low & 0.13 & 0.096 & 0.117 \\
\hline Medium & 0.111 & 0.0873 & 0.123 \\
\hline High & 0.18 & 0.23 & 0.26 \\
\hline
\end{tabular}

TABLE VI

RULE BASE FOR SPEED ERROR $=$ POSITIVE

\begin{tabular}{|c|c|c|c|}
\cline { 2 - 4 } \multicolumn{1}{c|}{} & \multicolumn{3}{c|}{ Acceleration } \\
\hline Actual Speed & Negative & Centre & Positive \\
\hline Low & 0.198 & 0.241 & 0.244 \\
\hline Medium & 0.281 & 0.306 & 0.355 \\
\hline High & 0.345 & 0.45 & 0.47 \\
\hline
\end{tabular}

The behavior of this controller can be improved by using a better database. In particular, since the neural network did not start with an expert trainer, some mistakes were necessarily carried over, and an improvement would be expected if one had exact pedal pressures produced by an expert driver.

\section{Simulation Results}

As noted above, to evaluate the closed-loop system's behavior with each of the controllers, the vehicle's dynamics were simulated with a model that takes the wheels, tire, brake, and engine dynamics into account.

Corrupting measurement noise from the speed and acceleration CAN-based sensors was modeled as additive white Gaussian variables, with the measured speed and acceleration being expressed as $V_{x_{m}}=V_{x}+\mathcal{N}(0, \sigma), \sigma=10^{-4}$ and $\gamma_{x_{m}}=$ $\gamma_{x}+\mathcal{N}(0, \sigma), \sigma=10^{-3}$, respectively.

In order to analyze the controllers' behavior over a wide operating range, several target speed changes were performed in first gear [see the setpoint and smooth reference speeds in Fig. 4(a)]. The quality of the tracking, the evolution of the control action, and the vehicle's resulting acceleration can be observed in the three plots of Fig. 4 for the four controllers, which summarize the most important aspects of the controllers' behavior.

In brief, all four controllers satisfy the Comfort Driving prerequisites, but with certain differences.

- The transient responses are different with the fuzzy-based control methods from those with the PI-based methods, especially in the convergence to the target speed. This is because PI controllers are designed to track a smoothed reference with bounded acceleration and jerk, whereas the regulation performed by fuzzy-based controllers is with respect to the final target speed.

- The steady-state response is satisfactory with three of the controllers, the exception being PI, but i-PI reaches the target value more accurately than either of the fuzzy-based controllers.

- The control actions are more abrupt in steady-state phases with the fuzzy controllers than with the PI controllers.
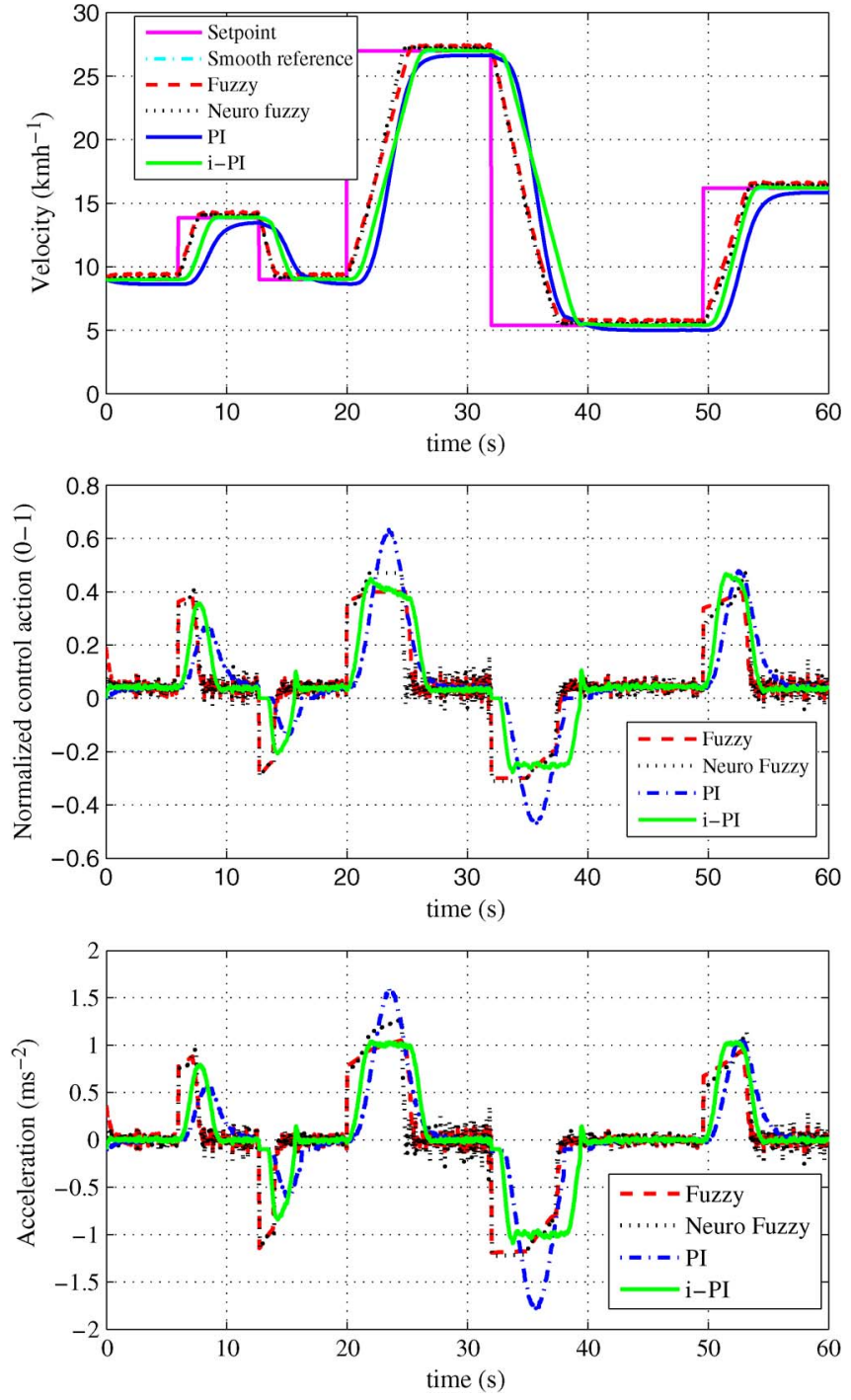

Fig. 4. Controller comparison: simulation. (a) Vehicle's speed (b) normalized actions of the accelerator $(0 / 1)$ and the brake $(-1 / 0)$ pedals; (c) acceleration.

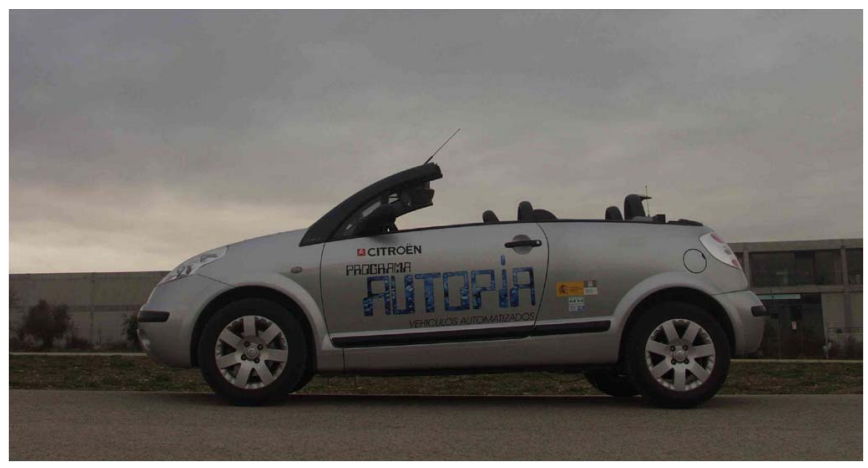

Fig. 5. Mass-produced car modified to permit autonomous longitudinal control.

\section{Automated Car}

After this design and check of the four controllers in a simulation, a mass-produced car was instrumented with control devices to test them in a real environment with a real car. In particular, this was a convertible Citroën C3 Pluriel (Fig. 5) modified to permit autonomous actions on the accelerator and brake pedals. These modifications allowed the controllers' outputs to be sent to the vehicle's actuators. 

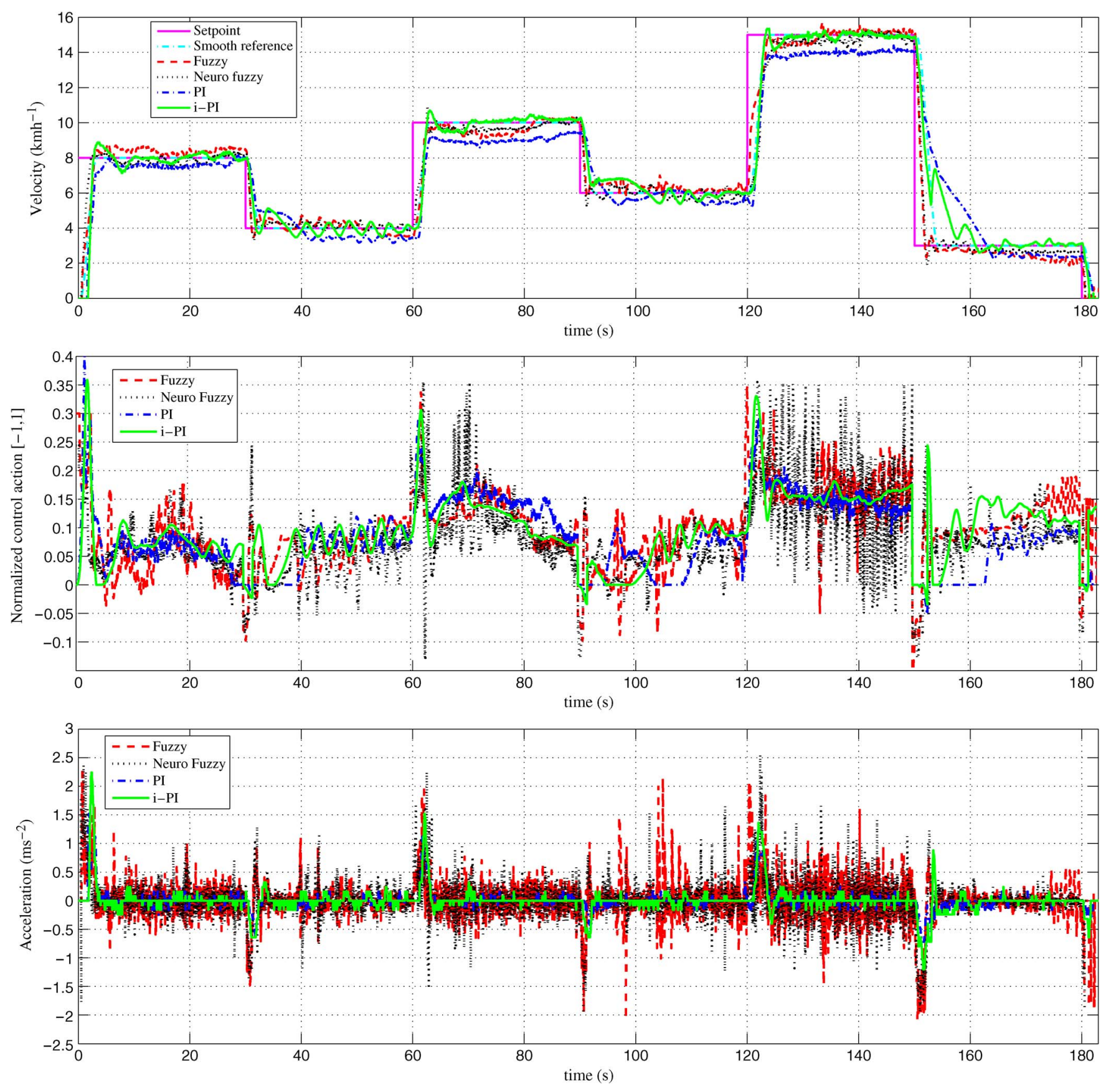

Fig. 6. Controller comparison: experimental. (a) Vehicle speed; (b) normalized actions of the accelerator (0/1) and the brake ( $-1 / 0)$ pedals; and (c) acceleration.

The car is equipped with an on-board industrial PC located in the boot that governs the various peripheral devices connected to it. A PCMCIA card is used to obtain the CAN bus data. Two different cards are connected to send the output control signals to the actuators. Details about throttle and brake automation processes can be found in [9] and [27].

As noted above, the control cycle rate is fixed by the CAN bus, with each $40 \mathrm{~ms}$, a new control signal being sent to the actuators. In the trials, the vehicle was motionless until a nonzero reference speed was received via software. To compare the controllers, a specific route was defined and the same reference speed changes were sent to them.

\section{EXPERIMENTAL RESULTS}

Various target speed changes were set each $30 \mathrm{~s}$, all within the very low speed range that was the object of the present study. To avoid any effect of gear changes, the automatic gearbox was maintained at all times in first gear.

Fig. 6 shows the results for each of the controllers. The upper plot depicts the vehicle's speed with respect to the target speed. The middle plot shows the action on the accelerator and brake pedals, with the values being normalized in the range $[0,1]$ to indicate an action on the accelerator and $[-1,0]$ for the brake. The lower plot is a reflection of the car's occupant comfort as given by the acceleration. 
TABLE VII

COMPARISON OF CONTROLLERS

\begin{tabular}{|c|c|c|c|c|c|}
\hline \multirow{2}{*}{ Contr. } & \multicolumn{2}{|c|}{ Control action } & \multicolumn{2}{c|}{ Track. err. (km/h) } & Mean comp. \\
\cline { 2 - 5 } & FFT median & max & mean & median & \\
\hline PI & $1.20 \cdot 10^{-4}$ & 0.39 & 1.188 & 0.660 & $4.13 \cdot 10^{-6}$ \\
i-PI & $1.24 \cdot 10^{-4}$ & 0.36 & 0.716 & 0.190 & $3.77 \cdot 10^{-6}$ \\
Fuzzy & $3.07 \cdot 10^{-4}$ & 0.35 & 0.629 & 0.360 & $3.71 \cdot 10^{-6}$ \\
N-fuzzy & $6.89 \cdot 10^{-4}$ & 0.35 & 0.543 & 0.250 & $6.60 \cdot 10^{-6}$ \\
\hline
\end{tabular}

To quantify these results, three principal control quality indicators will be compared (see Table VII): the absolute tracking error, the computational cost, and the softness of the control action. The first two can be computed directly from measurements. The last was estimated as the median frequency of the control action's Fast Fourier Transform (FFT).

FFT is an an efficient algorithm to compute the Discrete Fourier Transform (DFT) $\mathcal{F}$

$$
U_{k}=\mathcal{F}\left(u_{k}\right)=\sum_{i=0}^{N-1} u_{k} e^{\left(-\frac{2 \pi N}{k i}\right)}, \quad k=0 \ldots N-1
$$

where $u_{k}$ is the control action at time $t_{k}$ and $N$ is the length of the control action signal. It is well known that DFT allows to analyze the frequency spectrum of a sampled signal, and as a consequence, its sharpness. Two complementary statistical indicators will be taken from the control signal: the maximum value and the median $\tilde{u}$ of sequence $U_{k}$

$$
P\left(U_{k} \leqslant \tilde{u}\right) \geqslant \frac{1}{2} \wedge P\left(U_{k} \geqslant \tilde{u}\right) \geqslant \frac{1}{2}
$$

to have a good indicator of the overall control action while giving reduced importance to outliers.

Besides, two different parameters will be also considered to evaluate the tracking performance from the absolute speed error

$$
e\left(t_{k}\right)=\left|V_{r}\left(t_{k}\right)-V_{x}\left(t_{k}\right)\right|, \quad t_{k} \in[0, T]
$$

being $V_{r}$ the reference speed: the mean $\bar{e}=(1 / N) \sum_{k=0}^{N-1} e_{k}$ and the median $\tilde{e}$, that naturally weights the steady-state error

$$
P\left(e\left(t_{k}\right) \leqslant \tilde{e}\right) \geqslant \frac{1}{2} \wedge P\left(e\left(t_{k}\right) \geqslant \tilde{e}\right) \geqslant \frac{1}{2} .
$$

One observes (see Fig. 6) that the PI controller was unable to attain the reference speed during the entire test. This is reflected in Table VII where the PI controller is the unique over the unity in the mean tracking error value. The behavior of the i-PI controller was excellent in response to positive reference speed changes in both transient and steady states. In response to negative reference speed changes, it needed more time to reach the steady state - as can be seen in the change from 15 to $3 \mathrm{~km} / \mathrm{h}$. This effect is mainly due to the fact that, for comfort reasons, the throttle is allowed to act slightly before the set-point is attained in braking maneuvers. While the fuzzy controller improved the results for negative reference speed changes, it presented large fluctuations in the steady state. The neuro-fuzzy controller corrected these fluctuations, but its behavior in the steady state was somewhat poorer (see the median tracking value in Table VII) than the i-PI controller.

The action on the actuators-i.e., on the accelerator and brake pedals-was significantly softer in the i-PI controller than in the fuzzy and neuro-fuzzy controllers, as is reflected in the car's acceleration. Despite all the controllers satisfying the Comfort Driving pre-requisites, the fluctuations were smaller with the i-PI controller (see the control action FFT median in Table VII). The highest control action was obtained by the PI controller.

Finally, mean computational cost (see Table VII) is quite similar for all 4 controllers. The Neuro-Fuzzy controller obtained a slightly higher execution time.

In brief therefore, PI is a well-known technique but it gave the poorest controller. The fuzzy controller can be intuitively re-tuned and its behavior can be considered acceptable; the neuro-fuzzy controller is an improvement but at the cost of losing the re-tuning option; and the i-PI controller shows the best behavior in the steady state with the greatest comfort, confirming the findings of the simulation. However, the transient response is still an unresolved issue in i-PI, especially in braking maneuvers. This fact is mainly due to the hybrid nature of the actuator, and several solutions are under investigation to solve this problem using recent results (cf. e.g., [28]).

\section{CONCLUSION}

A comparative study of four control techniques has been presented: classical PI control, a novel control technique denominated i-PI control, fuzzy control based on human expert knowledge and experience, and neuro-fuzzy control. These controllers were designed, validated in simulations, and implemented in a mass-produced car. It was not only the goal of the study to compare different intelligent control techniques but also to try to respond to one of the unsolved problems of ADAS - speed control with a full-range capability, in particular, at the low speeds that occur in traffic jams. To this end, a mass-produced car-a Citroën C3 Pluriel—was modified to manage the accelerator and brake pedals autonomously to use it as a test-bed for the controllers.

The intelligent control techniques were implemented in this car using the on-board sensors without involving any additional cost in extra-sensorial information. Only a minimum of modifications were made to allow automatic action on the accelerator pedal via an analog card, and on the brake pedal via an electrohydraulic pump.

The controller comparison showed the PI controller to be unacceptable because of its large tracking error. The human knowledge based fuzzy controller presented good behavior as well as being easy and intuitive to re-tune via its rule base. Indeed, the time needed to design this controller was significantly shorter than needed for the others. The neuro-fuzzy controller gave better results but at the cost of it being difficult to change the rule base that was generated. Finally, the i-PI controller gave the best behavior as measured by the averages of the quality parameters tested. Its main drawback is in its tracking of negative reference speed changes.

From the ADAS point of view, we have presented the design and implementation of three valid solutions for an as yet unresolved issue in the automotive sector-automatic speed control at very low speeds. The systems presented can be used to relieve the human driver of the type of tedious tasks that arise when driving in traffic jams. 


\section{REFERENCES}

[1] G. Bel and M. Nadal, "Anuario de la movilidad 2008," RACC, Barcelona, Spain, 2009.

[2] T. Aono and T. Kowatari, "Throttle-control algorithm for improving engine response based on air-intake model and throttle-response model," IEEE Trans. Ind. Electron., vol. 53, no. 3, pp. 915-921, Jun. 2006.

[3] S. Moon, I. Moon, and K. Yi, "Design, tuning and evaluation of a fullrange adaptive cruise control system with collision avoidance," Control Eng. Pract., vol. 17, no. 4, pp. 442-455, Apr. 2009.

[4] L. van Kampen, "Cruise control in personenauto's: Een literatuurorientatie op verkeersveiligheidsaspecten (cruise control in passenger cars)," SWOV, Leidschendam, The Netherlands, 1996.

[5] A. Lindgren, A. Angelelli, P. Mendoza, and F. Chen, "Driver behaviour when using an integrated advisory warning display for advanced driver assistance systems," IET Intell. Transp. Syst., vol. 3, no. 4, pp. 390-399, Dec. 2009.

[6] A. Girard, S. Spry, and J. Hedrick, "Intelligent cruise control applications: Real-time embedded hybrid control software," IEEE Robotics \& Automation Magazine, vol. 12, no. 1, pp. 22-28, Mar. 2005.

[7] L. Cai, A. Rad, and W. L. Chan, "An intelligent longitudinal controller for application in semi-autonomous vehicles," IEEE Trans. Ind. Electron., vol. 57, no. 4, pp. 1487-1497, Apr. 2010.

[8] "Compendium of executive summaries from the Maglev system concept definition final reports," U.S. Dept. Transp., Washington, DC, Mar. 1993.

[9] V. Milanés, C. González, J. Naranjo, E. Onieva, and T. de Pedro, "Electrohydraulic braking system for autonomous vehicles," Int. J. Automot. Technol., vol. 11, no. 1, pp. 89-95, 2010.

[10] R. Rajamani, Vehicle Dynamics and Control. New York: SpringerVerlag, 2005.

[11] H. Pacejka and E. Bakker, "The magic formula tyre model," Vehicle Syst. Dyn., vol. 21, pp. 1-18, 2004.

[12] K. Aström and T. Hägglund, Advanced PID Controllers. Research Triangle Park, NC: Instrument Soc. Amer., 2006.

[13] S. Choi, B. D'Andréa-Novel, M. Fliess, H. Mounier, and J. Villagra, "Model-free control of automotive engine and brake for stop-and-go scenarios," in Proc. Eur. Control Conf., 2009, pp. 3622-3627.

[14] V. Milanés, E. Onieva, J. Pérez, T. de Pedro, and C. González, "Control de velocidad adaptativo para entornos urbanos congestionados," Revista Iberoamericana de Automática e Informática Industrial, vol. 6, no. 4, pp. 66-73, Oct. 2009.

[15] S. Cong and Y. Liang, "PID-like neural network nonlinear adaptive control for uncertain multivariable motion control systems," IEEE Trans. Ind. Electron., vol. 56, no. 10, pp. 3872-3879, Oct. 2009.

[16] J. Wang, C. Fu, and Y. Zhang, "SVC control system based on instantaneous reactive power theory and fuzzy PID," IEEE Trans. Ind. Electron., vol. 55, no. 4, pp. 1658-1665, Apr. 2008.

[17] G. Liping, J. Hung, and R. Nelms, "Evaluation of DSP-based PID and fuzzy controllers for dc-dc converters," IEEE Trans. Ind. Electron., vol. 56, no. 6, pp. 2237-2248, Jun. 2009.

[18] M. Fliess and C. Join, "Model-free control and intelligent pid controllers: Towards a possible trivialization of nonlinear control?" in Proc. 15th IFAC SYSID, 2009.

[19] K. Youcef-Toumi and O. Ito, "A time delay controller for systems with unknown dynamics," in Proc. Amer. Control Conf., 1988, pp. 904-913.

[20] J. Han, "From PID to active disturbance rejection control," IEEE Trans. Ind. Electron., vol. 56, no. 3, pp. 900-906, Mar. 2009.

[21] J. Villagra, V. Milanés, J. Pérez, and T. de Pedro, "Control basado en pid inteligentes: Aplicación al control robusto de velocidad en entornos urbanos," Revista Iberoamericana de Automática e Informática Industrial, vol. 7, no. 4, pp. 44-52, 2010.

[22] S. Huang and W. Ren, "Vehicle longitudinal control using throttles and brakes," Robot. Auton. Syst., vol. 26, no. 4, pp. 241-253, Mar. 1999.

[23] M. Sugeno and M. Nishida, "Fuzzy control of model car," Fuzzy Sets Syst., vol. 16, no. 2, pp. 103-113, Jul. 1985.

[24] J.-S. R. Jang, "ANFIS: Adaptive-network-based fuzzy inference system," IEEE Trans. Syst., Man, Cybern., vol. 23, no. 3, pp. 665-685, May/Jun. 1993.

[25] R. Vatankhah, M. Rahaeifard, and A. Alasty, "Vibration control of vehicle suspension system using adaptive critic-based neurofuzzy controller," in Proc. 6th ISMA, 2009, pp. 221-224.
[26] J. Perez, A. Gajate, V. Milanes, E. Onieva, and M. Santos, "Design and implementation of a neuro-fuzzy system for longitudinal control of autonomous vehicles," in Proc. IEEE WCCI, Apr. 14-17, 2010, pp. 1-5.

[27] V. Milanés, D. F. Llorca, B. M. Vinagre, C. González, and M. A. Sotelo, "Clavileño: Evolution of an autonomous car," in Proc. 13th IEEE ITSC, 2010, pp. 1129-1134.

[28] R. Bourdais, M. Fliess, C. Join, and W. Perruquetti, "Towards a modelfree output tracking of switched nonlinear systems," in Proc. 7th IFAC Symp. Nonlinear Control Syst., 2007, pp. 637-642.

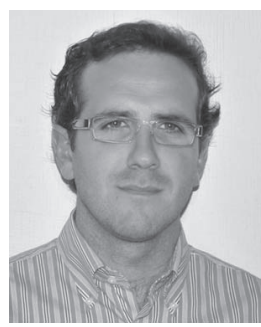

Vicente Milanés was born in Badajoz, Spain, in 1980. He received the B.E. and M.E. degrees in electronic engineering from the Extremadura University, Badajoz, in 2002 and 2006, respectively, and the Ph.D. degree in electronic engineering from the Alcala University (UAH), Madrid, Spain, in 2010.

Since 2006, he has been with the Spanish National Research Council, presently at the Center for Automation and Robotics, Madrid, Spain. His research interests include autonomous vehicles, fuzzy-logic control, intelligent traffic and transport infrastructures, vehicle-infrastructure cooperation, and intelligent transportation systems (ITS).

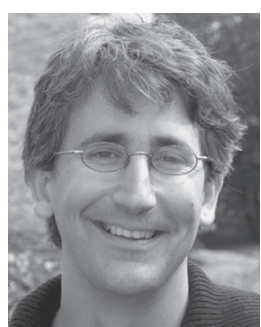

Jorge Villagrá graduated in Electrical Engineering at the Universidad Politécnica of Madrid, Madrid, Spain, in 2002. He received the Ph.D. degree in Real-Time Computer Science, Robotics and Automatic Control at the Ecole des Mines de Paris, Paris, France, in 2006.

From 2006 to 2009, he was consecutively a research assistant at INRIA-Roquencourt (France) and a Visiting Professor at the University Carlos III, Madrid, Spain. He is currently a research fellow at the Program AUTOPIA in the Center for Automation and Robotics UPM-CSIC (Spain). His research interests include on the one hand, nonlinear and optimal control and nonlinear estimation for intelligent transportation systems, and on the other hand, robust control systems for humanoid and mobile robotic applications.

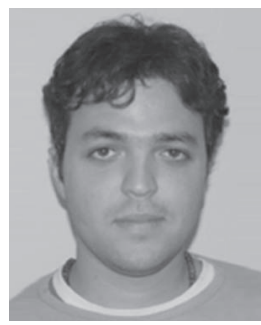

Joshué Pérez was born in Coro, Venezuela, in 1984. He received the B.E. degree in electronic engineering from the Simón Bolívar University, Caracas, Venezuela, in 2007, and the M.E. degree in system engineering and automatic control from the University Complutense of Madrid, Madrid, Spain, in 2009. $\mathrm{He}$ is currently working toward the Ph.D. degree in the Center for Automation and Robotics, Madrid.

His research interests includes fuzzy logic, modeling, control and cooperative maneuvers among autonomous vehicles.

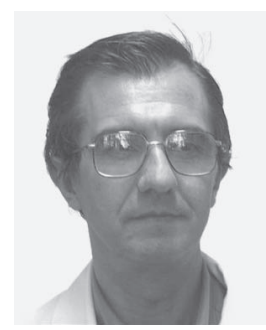

Carlos González (M'86) was born in Torrelavega, Cantabria, Spain, in 1947. He received the B.S. and $\mathrm{Ph} . \mathrm{D}$. degrees in physics from Madrid University, Madrid, Spain, in 1969 and 1978, respectively, and the M.S. degree in computer science from University of California, Los Angeles, in 1974.

Since 1971, he has been with the Consejo Superior de Investigaciones Científicas, presently in the Centro de Automática y Robótica, Madrid. He is also a Software Specialist for automation projects. 